\title{
Research Paper: Investigating the Psychometric Properties of Self-criticism and Self-reassurance Scale in Iranian Students
}

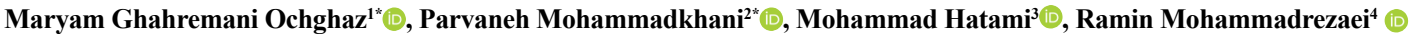

1. Department of Health Psychology, Kish International Branch, Islamic Azad University, Kish Island, Iran.

2. Department of Clinical Psychology, University of Social Welfare and Rehabilitation Sciences, Tahran, Iran.

3. Department of Psychology, Kharazmi University, Tehran, Iran.

4. Center of Tehran Heart, Tehran University of Medical Sciences, Tehran, Iran

\begin{tabular}{|c|c|}
\hline $\begin{array}{l}\text { Uss yuur device to scan } \\
\text { and read the artice online }\end{array}$ & ditert on:- Ghahremani Ochghaz P, Mohammadkhani P, Hatami M, Mohammadrezaei R. (2020). Stigating the Psychometric \\
\hline$\square$ & $\begin{array}{l}\text { Properties of Self-criticism and Self-reassurance Scale in Iranian Students. Journal of Practice in Clinical Psychology, 8(1), 65-72. } \\
\text { https://doi.org/10.32598/jpcp.8.1.67 }\end{array}$ \\
\hline acte & doi https://doi.org/10.32598/jpcp.8.1.67 \\
\hline
\end{tabular}

(c) (i) (8)

Article info:

Received: 10 Jun 2019

Accepted: 25 Oct 2019

Available Online: 01 Jan 2020

Keywords:

Self-criticism and Selfreassurance Scale (SCSRS), Students, Psychometrics

\section{ABSTRACT}

Objective: This research investigated the psychometric properties of the Self-criticism Scale (SCS) and Self-reassurance Scale (SRS) among the students in Tehran universities.

Methods: First, the original versions of SCS and SRS were translated into Persian and backtranslated into English. Then, the scales were reviewed and revised by Psychology professors and experts. Finally, the 22 -item scale was presented to 300 students from Tehran universities.

Results: Using Explanatory Factor Analysis (EFA), three items were removed, and the 3-factor structure of the questionnaire was supported. The reliability of each factor was also calculated using Cronbach's alpha coefficient and was at an acceptable level. Generally, stability and reliability coefficients for SCR and SRS were satisfactory $(\mathrm{P}<0.05)$.

Conclusion: SRS and SCS, form a homogenous set with the appropriate factorial structure qualified for psychological investigations and clinical application in Iranian society.

\section{* Corresponding Author:}

Parvaneh Mohammadkhani, PhD.

Address: Department of Clinical Psychology, University of Social Welfare and Rehabilitation Sciences, Tahran, Iran.

Tel: +98 (21) 22180045

E-mail: parmohamir@yahoo.com
* Corresponding Author:

Maryam Ghahremani Ochghaz, PhD.

Address: Department of Health Psychology, Kish International Branch, Islamic Azad University, Kish Island, Iran

Tel: +98 (902) 9423985

E-mail: maryam_ghahremani@yahoo.com 


\section{Highlights}

- An investigation of the psychometric properties of the Self-criticism Scale (SCS) and Self-reassurance Scale (SRS);

- SRS and SCS form a homogenous set with the appropriate factorial structure qualified for psychological investigations and clinical application.

\section{Plain Language Summary}

This research investigated the psychometric properties of the Self-criticism Scale (SCS) and Self-reassurance Scale (SRS). First, the original versions of SCS and SRS were translated into Persian and back-translated into English ad then reviewed and revised. The scale was presented to the students. The reliability of each factor was also calculated using Cronbach's alpha coefficient. The stability and reliability coefficients for SCR and SRS were satisfactory. In general, SRS and SCS form a homogenous set with the appropriate factorial structure qualified for psychological investigations and clinical application in Iranian society.

\section{Introduction}

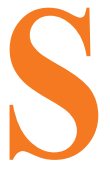

trict self-assessment is among the most critical psychological processes affecting the persistence and relapse of psychopathology signs and symptoms (Falconer, King, \& Brewin, 2015; Pagura, Cox, Sareen, \& Enns, 2006). Strict self-assessment is conceptualized through acute self-criticism and limited self-reassurance (Duarte et al., 2017). Maladaptive self-criticism can be defined as a continuous tendency toward negative self-assessment leading to prudency and self-devaluation (Falconer et al., 2015). This negative attitude toward oneself has connected to the deficiency of a lack of emotional bonds and relationships in one's early life stages (Sachs-Ericsson, Verona, Joiner, \& Preacher, 2006). It is also connected to broader psychological issues, such as depression (Yamaguchi \& Kim, 2013), stress and cognitive disturbances (Longe et al., 2010), mood swing (Falconer et al., 2015), as well as emotional dysregulation and failure to adhere treatment regimens (Duarte et al., 2017).

Trict self-assessment is among the most critical psychological processes affecting the persistence and relapse of psychopathology signs and symptoms (Falconer, King, \& Brewin, 2015; Pagura, Cox, Sareen, \& Enns, 2006). Strict self-assessment is conceptualized through acute self-criticism and limited self-reassurance (Duarte et al., 2017). Maladaptive self-criticism can be defined as a continuous tendency toward negative self-assessment leading to prudency and selfdevaluation (Falconer et al., 2015). This negative attitude toward oneself has connected to the deficiency of a lack of emotional bonds and relationships in one's early life stages (Sachs-Ericsson, Verona, Joiner, \& Preacher, 2006). It is also connected to broader psychological issues, such as depression (Yamaguchi \& Kim, 2013), stress and cognitive disturbances (Longe et al., 2010), mood swing (Falconer et al., 2015), as well as emotional dysregulation and failure to adhere treatment regimens (Duarte et al., 2017).

By specifying the presumed self-value and capabilities, the quality of self-criticism and self-reassurance determines his/her encounter with the outer world, past, and future. It can also generate signs, such as rumination, negative predictions, and anxiety towards the future (Gilbert, 2010). The value and importance one presumes for self are connected to his/her self-assessment (Kupeli, Chilcot, Schmidt, Campbell, \& Troop, 2013). Individuals reach equilibrium by self-assessment through selfcriticism and self-reassurance; thus, any inconsistency in these structures can lead to psychological disorders and aggravate pathological signs (Duarte et al., 2017). Therefore, precise knowledge about one's self-assessment can be a prerequisite in his/her successful therapy; therefore, measuring self-criticism and self-reassurance is of great importance (Kupeli et al., 2013). As a result, the design and implementation of measuring tools for self-criticism and self-reassurance structures require adequate research attention (Falconer et al., 2015).

Forms of Self-criticism and Self-reassurance Scale (FSCRS) is a tool with a vast research background designed for measuring self-criticism and self-reassurance (Gilbert, Clarke, Hempel, Miles, \& Irons, 2004). With 22 items, this tool investigates the thoughts and emotions of different people towards self in undesired situations. This scale includes three components; two self- 
criticism and one about self-reassurance. According to the primary factor analysis conducted by Gilbert et al. (2004), two types of self-criticism were identified. These types included self-incompetence focused on one's insufficiency, and self-hatred, i.e. one's tendency toward hurting and hating self. Besides, the factor analysis conducted by Gilbert et al. (2004) indicated that the items related to reassurance, belong to a single factor, like selfreassurance component. This component is connected to the ability to encourage and support oneself in confronting different problems. Cronbach's alpha coefficients for this measure in Gilbert et al. (2004) research were reported as $90 \%$ for self-incompetence, $86 \%$ for selfhatred, and $86 \%$ for self-reassurance.

Kupeli et al. (2013) also investigated the reliability and stability of SCRS. Their results indicated that the three-factor model for this scale (self-incompetence, self-hatred, and self-reassurance) provides the best structure for measuring the quality of self-criticism and self-reassurance. In this research, the difference between the two types of self-criticism was confirmed. Moreover, the obtained findings indicated that all factors were as stable as those achieved by Gilbert et al. (2004). Another study explored the latent structure of the FSCRS in nonclinical and clinical samples (Castilho, Pinto-Gouveia, \& Duarte, 2015). Their results supported the three-factor model for this scale. Additionally, they suggested internal consistency coefficients for self-inadequacy (89\%), self-hatred (62\%), and self-reassurance (87\%) factors. In research by Carreiras (2014), after performing an Explanatory Factorial Analysis (EFA), the three obtained factors by Gilbert et al. (2004) were supported. Accordingly, Cronbach's alpha coefficient for self-incompetency (89\%), self-hatred $(81 \%)$, and self-reassurance were obtained.

Applying psychological tests without considering sociocultural factors can lead to some misinterpretations. Besides, a review of the scales existing in Iran indicates a lack of qualified tests examining self-criticism and selfreassurance concepts. However, considering the collectivist culture of Iran, individuals have always exposed themselves to acute and maladaptive self-criticisms and endured their consequences. Therefore, credible selfcriticism and self-reassurance tools can help clinicians in measuring, diagnosing, and planning treatment programs. Consequently, such measures could increase psychological knowledge in terms of negative and positive self-assessment. Thus, assessing the psychometric properties of such inventories seems necessary. SRS and SCS could be employed in the Iranian population. Therefore, this research investigated the reliability and stability of this questionnaire on an Iranian population.

\section{Methods}

This cross-sectional study evaluated the psychometric properties of SRS and SCS. The study sample included 300 students from Tehran universities. They were selected using a convenience sampling method. Table 1 presents the study sample's characteristics in terms of gender, education, age, and marital status.

The Self-Criticism and Self-Reassurance Scale (SCSRS) was designed by Gilbert et al. (2004). This scale measures the severity of self-criticism and the ability of self-reassuring. This 22-item scale investigates the thoughts and emotions of individuals towards self in undesired situations. This scale includes three components. Two components cover self-criticism; self-incompetence focuses on one's insufficiency (I become disappointed with myself quickly) and self-hatred, i.e. one's tendency toward hurting and hating self (I am so mad at myself that I want to hurt myself). Another component is about self-reassurance, encouraging, and supporting oneself (I can remind myself of my positive aspects). The items are responded on a 5 -point Likert-type scale $(0=$ completely disagree; 4=completely agree). Cronbach's alpha coefficient for this measure has been obtained by Gilbert et al. (2004), self-incompetence (90\%), self-hatred (86\%), and self-reassurance $(86 \%)$.

First, the questionnaire was translated into Persian. Then, it was back-translated to English by a bilingual English expert. Next, the two forms of the original SCRS and the translated one were compared by another English language expert. Accordingly, the questionnaire was revised according to the suggested comments. The final translated SCRS was reviewed and approved by Psychology professors and experts. Eventually, a 22-item questionnaire in Persian was presented to the study participants to complete it on a 5-point Likert-type scale. The study participants were informed about the study purposes. Furthermore, they were assured about the confidentiality of their data and informed that their participation in the study was voluntary.

\section{Results}

The questionnaire was distributed among 300 students with different educational status, study fields, ages, etc. background. The statistical analyses were conducted on the data obtained from the collected questionnaires. 
Table 1. The demographic characteristics of study subjects

\begin{tabular}{|c|c|c|c|}
\hline Index & Group & No. & $\%$ \\
\hline \multirow{2}{*}{ Gender } & Male & 134 & 44.7 \\
\hline & Female & 166 & 55.3 \\
\hline \multirow{4}{*}{ Education } & Associate degree & 28 & 9.3 \\
\hline & BA & 159 & 53.0 \\
\hline & MA & 95 & 31.7 \\
\hline & PhD. & 18 & 6.0 \\
\hline \multirow{2}{*}{ Marital Status } & Single & 176 & 58.7 \\
\hline & Married & 124 & 41.3 \\
\hline \multirow{6}{*}{ Age (y) } & $<20$ & 27 & 9.0 \\
\hline & $20-25$ & 90 & 30.0 \\
\hline & $25-30$ & 85 & 28.3 \\
\hline & $30-35$ & 48 & 16.0 \\
\hline & $35-40$ & 30 & 10.0 \\
\hline & $>40$ & 20 & 6.7 \\
\hline
\end{tabular}

The first step to implement the factorial analysis on a set of items was to conduct the Kaiser-Meyer-Olkin (KMO) test and Bartlett's test of sphericity. The Bartlett's test is significant at $>0.0005$ level with a degree of freedom of 231. Furthermore, the KMO test value (1893.07) was obtained at $62 \%$. This finding indicated that the questions in SCRS were sufficient for establishing the correlated factors; thus, we could employ the factor analysis method.

Factor loadings $<15 \%$ are a problem for factor analysis iterations and factor loadings $>35 \%$ can eliminate many questions. Therefore, in this research, the minimum factor loading was selected as $21 \%$. Moreover, 22 items of SCRS were investigated using EFA and the main component and Varimax rotation method. As per Table 2, the eigenvalue of factors 1 to 3 was $>1.5$, suggesting that three specific factors with eigenvalues $>1.5$ are extractable.
To extract the number of factors, we considered the explained variance by each factor and the Scree plot. Before investigating the Scree test, the variances explained by the factor (Table 2) revealed that before rotation, the first, second, and third factors explained $16.25 \%, 14.07 \%$, and $8.3 \%$ of the total variance. Given the variance value explained by each factor, the three factors were considered as proper for the analysis; thus, the Scree plot was also considered to finalize the decision about the number of factors (Figure 1). Table 3 lists the factor loading of SCRS after rotation in the Varimax method.

Considering the highest level of factor loading in the three factors, the three-factor model of SCRS was supported. However, in the present research, items 8, 14, and 19 were unable to capture the appropriate factor loading; therefore, they were eliminated from the questionnaire.

Table 2. Initial eigenvalues and eigenvalues after the of SCRS

\begin{tabular}{ccccc}
\hline \multirow{2}{*}{ Factor } & \multicolumn{2}{c}{ Initial Eigenvalues } & \multicolumn{2}{c}{ Sum of Squares After Rotation } \\
\cline { 2 - 5 } & Eigenvalue & Variance (\%) & Eigenvalue & Variance (\%) \\
\hline 1 & 3.575 & 16.25 & 3.006 & 13.66 \\
2 & 3.094 & 14.07 & 2.822 & 12.83 \\
3 & 1.827 & 8.3 & 2.105 & 9.57 \\
\hline
\end{tabular}




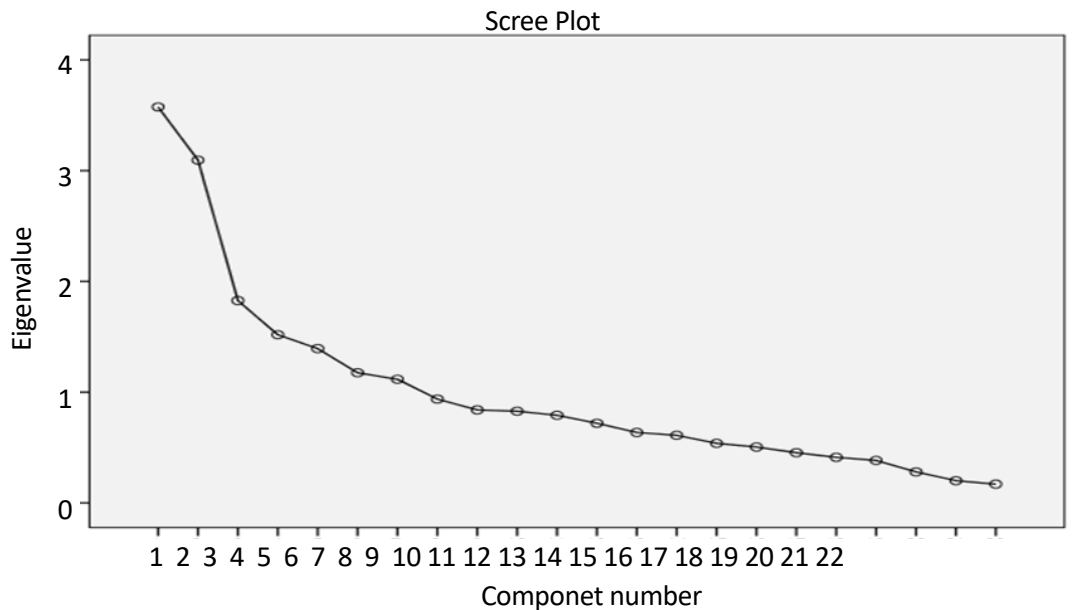

Figure 1. The scree test for identifying the number of factors

The first component is related to self-incompetency and focuses on self-insufficiency. This factor includes items $1,2,4,6,7,17,18$, and 20.

The second component is related to self-reassurance, i.e. indicated by supporting and encouraging oneself. This factor includes items 3, 5, 11, 13, 16, and 21 .

Table 3. Rotational matrix for the three factors in SCRS
The third component is related to self-hatred, indicating one's tendency to hurt self. This factor includes items $9,10,12,15$, and 22 .

Table 4 demonstrates the correlational matrix of the three extracted factors from SCRS.

As observed, there was a significant negative relationship between self-reassurance and self-hatred. Cron-

\begin{tabular}{|c|c|c|c|}
\hline Items & Factors 1 & Factors 2 & Factors 3 \\
\hline 1 & 0.459 & - & - \\
\hline 2 & 0.679 & - & - \\
\hline 4 & 0.833 & - & - \\
\hline 6 & 0.796 & - & - \\
\hline 7 & 0.428 & - & - \\
\hline 17 & 0.215 & - & - \\
\hline 18 & 0.369 & - & - \\
\hline 20 & 0.475 & - & - \\
\hline 3 & - & 0.742 & - \\
\hline 5 & - & 0.838 & - \\
\hline 11 & - & 0.568 & - \\
\hline 13 & - & 0.495 & - \\
\hline 16 & - & 0.502 & - \\
\hline 21 & - & 0.610 & - \\
\hline 9 & - & - & 0.318 \\
\hline 10 & - & - & 0.438 \\
\hline 12 & - & - & 0.707 \\
\hline 15 & - & - & 0.737 \\
\hline 22 & - & - & 0.580 \\
\hline
\end{tabular}


Table 4. The correlational matrix of the factors extracted from SCRS

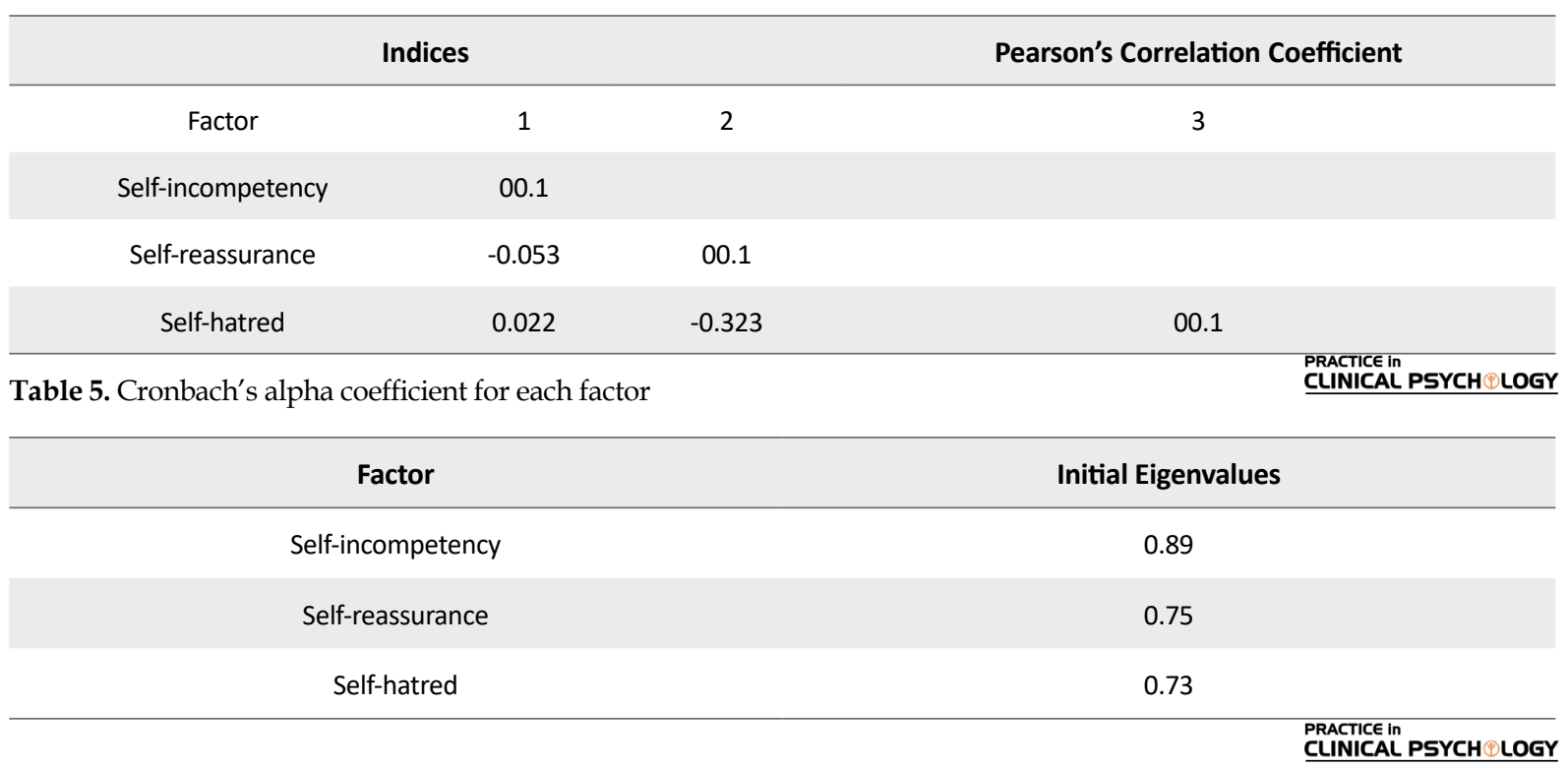

bach's alpha coefficient was used to investigate the stability of this study. Table 5 presents the obtained Cronbach's alpha coefficient for each factor. Cronbach's alpha coefficient for the three factors of the questionnaire was acceptable.

\section{Discussion}

The study findings suggested that the reliability and stability of SCRS are acceptable. The results obtained from the factor analysis revealed that this questionnaire is well-structured and is consistent with the one developed by Gilbert et al. (2004). The EFA results introduced the three factors extracted from the questionnaire items. These data are as follows: self-incompetency factor with 8 items, investigating self-insufficiency and inability to confront any problem; self-reassurance factor with 6 items, measuring the support and encouragement toward oneself; and self-hatred factor with 5 items, denoting the severity of hatred towards oneself. Consistent with the findings of this research, Kupeli et al. (2013), Castilo and Pintogia (2011), and Carreiras (2014) demonstrated the three-factor structure for SCRS. Therefore, the items related to each factor can easily predict the quantity and quality of self-criticism and self-reassurance. Thus, this scale can be employed in psychological research studies as well as in diagnosing and treating mental disorders.

A low correlation between self-incompetency and selfhatred in the present research indicated that there were two different types of self-criticism in the Iranian population's strict self-assessment. This finding is consistent with those of Gilbert et al. (2004), Kupeli et al. (2013), Castilo and Pintogia (2011), and Carreiras (2014), where two types of self-criticism, including self-incompetency and self-hatred, were mentioned.

Cronbach's alpha coefficient for the factors of SCRS was in a desirable range. The reliability coefficients were obtained for self-incompetency (0.89), self-reassurance (0.75), and self-hatred (0.73). Similar results were obtained by Gilbert P et al. (2004), Kupeli et al. (2013), Castilo and Pintogia (2011), and Carreiras (2014).

The findings of this research and previous investigations indicated that SCRS is highly reliable. Generally, the present findings reflected that SCRS is of high psychometrically-qualified properties. Nevertheless, it is essential to acknowledge some limitations in the present study. First, the study sample was limited to students; thus, generalizability to the general and clinical population should be made consciously. Second, the present study investigated the EFA of SCRS; it is recommended that future research investigates the divergent and convergent reliability of this questionnaire through a correlation coefficient with similar or different constructs in other psychological scales. Additionally, a review of the factorial structure using confirmatory factor analysis is necessary to ensure the compe tency of the factorial structure and the reliability of the scale's construct. For a more precise development of SCRS, it is also recommended to use re-test method to improve the accuracy of this scale for diagnostic studies. 


\section{Conclusion}

SRS and SCS, form a homogenous set with the appropriate factorial structure qualified for psychological investigations and clinical application in Iranian society.

\section{Ethical Considerations}

\section{Compliance with ethical guidelines}

All ethical principles were considered in this article. The participants were informed about the purpose of the research and its implementation stages; they were also assured about the confidentiality of their information; Moreover, They were allowed to leave the study whenever they wish, and if desired, the results of the research would be available to them.

\section{Funding}

This research did not receive any specific grant from funding agencies in the public, commercial, or not-forprofit sectors.

\section{Authors' contributions}

All authors contributed equally in preparing all parts of the research.

\section{Conflict of interest}

The authors declared no conflict of interest.

\section{References}

Castilho, P., Pinto-Gouveia, J., \& Duarte, J. (2015). Exploring selfcriticism: Confirmatory factor analysis of the FSCRS in clinical and nonclinical samples. Clinical Psychology \& Psychotherapy, 22(2), 153-64. [DOI:10.1002/cpp.1881] [PMID]

Duarte, C., Stubbs, J., Pinto-Gouveia, J., Matos, M., Gale, C., \& Morris, L. (2017). The impact of self-criticism and self-reassurance on weight-related affect and well-being in participants of a commercial weight management programme. Obesity Facts, 10(2), 65-75. [DOI:10.1159/000454834] [PMID] [PMCID]

Falconer, C. J., King, J. A., \& Brewin, C. R. (2015). Demonstrating mood repair with a situation-based measure of self-compassion and self-criticism. Psychology and Psychotherapy: Theory, Research and Practice, 88(4), 351-65. [DOI:10.1111/papt.12056] [PMID] [PMCID]

Gilbert, P. (2010). Compassion focused therapy. United Kingdom Distinctive features: Routledge. [DOI:10.4324/9780203851197]
Gilbert, P., Clarke, M., Hempel, S., Miles, J. N., \& Irons, C. (2004). Criticizing and reassuring oneself: An exploration of forms, styles and reasons in female students. British Journal of Clinical Psychology, 43(1), 31-50. [DOI:10.1348/01446650477281295 9] [PMID]

Gilbert, P., McEwan, K., Mitra, R., Franks, L., Richter, A., \& Rockliff, H. (2008). Feeling safe and content: A specific affect regulation system? Relationship to depression, anxiety, stress, and self-criticism. The Journal of Positive Psychology, 3(3), 18291. [DOI:10.1080/17439760801999461]

Kupeli, N., Chilcot, J., Schmidt, U. H., Campbell, I. C., \& Troop, N. A. (2013). A confirmatory factor analysis and validation of the forms of self-criticism/reassurance scale. British Journal of Clinical Psychology, 52(1), 12-25. [DOI:10.1111/j.20448260.2012.02042.x] [PMID]

Leary, M. R., Tate, E. B., Adams, C. E., Batts Allen, A., \& Hancock, J. (2007). Self-compassion and reactions to unpleasant self-relevant events: The implications of treating oneself kindly. Journal of Personality and Social Psychology, 92(5), 887. [DOI:10.1037/0022-3514.92.5.887] [PMID]

Longe, O., Maratos, F. A., Gilbert, P., Evans, G., Volker, F., \& Rockliff, H. (2010). Having a word with yourself: Neural correlates of self-criticism and self-reassurance. NeuroImage, 49(2), 1849-56. [DOI:10.1016/j.neuroimage.2009.09.019] [PMID]

Pagura, J., Cox, B. J., Sareen, J., \& Enns, M. W. (2006). Childhood adversities associated with self-criticism in a nationally representative sample. Personality and Individual Differences, 41(7), 1287-98. [DOI:10.1016/j.paid.2006.05.003]

Sachs-Ericsson, N., Verona, E., Joiner, T., \& Preacher, K. J. (2006). Parental verbal abuse and the mediating role of self-criticism in adult internalizing disorders. Journal of Affective Disorders, 93(1-3), 71-8. [DOI:10.1016/j.jad.2006.02.014] [PMID]

Yamaguchi, A., \& Kim, MS. (2013). Effects of self-criticism and its relationship with depression across cultures. International Journal of Psychological Studies, 5(1), 1. [DOI:10.5539/ijps. v5n1p1] 
This Page Intentionally Left Blank 